\title{
O teatro de origem não-dramatúrgica
}

\author{
José Eduardo Vendramini
}

ntendo por teatro não-dramatúrgico aquele que é criado diretamente no palco e não a partir de um texto, o que não impede que se possa chegar a ele, no final do processo. No Brasil, já houve este tipo de manifestação, de forma esporádica, caracterizando uma das vertentes do assim chamado teatro experimental. Porém, mais recentemente, a partir dos espetáculos que Gerald Thomas começou a fazer no Brasil, criou-se uma celeuma que deu origem à necessidade de organização do pensamento crítico a respeito. Assim, dada a quantidade, a qualidade de acabamento e o caráter provocativo de seus espetáculos, as pessoas tiveram que se posicionar.

Foi preciso, em primeiro lugar, situar que tipo de teatro era esse a que se estava assistindo; em segundo, estabelecer o que se pensava a respeito; e, em terceiro, em sala de aula, decidir o que dizer em termos sistematizadores, pois, apesar de os alunos terem total liberdade quanto às suas escolhas estéticas, o docente precisa se posicionar, por necessidade da profissão.

A razão do tema foi o aparecimento de um determinado tipo de teatro, que rompeu com o dramaturgo tradicional, prescindindo da figura do Autor. Aquele velho costume de se pegar uma peça de teatro para montar, passou a ter uma variante perturbadora. E é desse tipo de teatro que eu vou falar. Mas, para isso, eu vou ter que voltar atrás, aos gregos, para lembrar como eram os fios principais que existiram e que fio esse novo tipo de teatro - que prescinde do dramaturgo, que começa direto no palco, que é feito pelo diretor - cortou.

Existe uma tese de doutoramento recente (Memória e Invenção: Gerald Thomas em Cena), já publicada, de autoria de Sílvia Fernandes, que informa, por exemplo, que as idéias dele às vezes partem de desenhos, os quais se transformam em cenas. Portanto, ele é um dramaturgo-diretor, ou um diretor-dramaturgo, como quiserem, mas sua base não é obrigatoriamente um texto, diálogos, conflitos, enredo.

Esta palestra não é especificamente sobre Gerald Thomas, mas sobre uma vertente que apareceu recentemente e da qual ele é emblemático.

Voltando um pouco no tempo, percebese que sempre se trabalha com modelos, deixados pela história do teatro. Na Grécia, cinco séculos antes de Cristo, houve o auge da tragédia.

José Eduardo Vendramini é professor Titular do Departamento de Artes Cênicas da ECA-USP, dramaturgo e encenador. 
No século seguinte, Aristóteles teorizou a respeito, tomando Édipo Rei, de Sófocles, como a tragédia modelo. Em sua Poética, há predominantemente uma teoria do texto dramatúrgico e muito pouco sobre o espetáculo.

Com o tempo, a Poética foi adquirindo uma importância cada vez maior, principalmente a partir do Renascimento, com a revalorização dos autores gregos e romanos. Assim, a obra de Aristóteles foi transformada num modelo de como fazer teatro, utilizado - durante o NeoClassicismo - como parâmetro para diferenciar os bons dos maus escritores. A obediência às regras passou a ser uma camisa-de-força para os artistas; alguns deles, excelentes, por não fazerem peças de acordo com as regras, eram menosprezados, ao passo que outros, medíocres, eram elogiados por obedecê-las cegamente.

Por sua importância e influência, a Poética acabou fornecendo um modelo de como escrever teatro e, como uma decorrência natural, um modelo de como dirigir teatro. Ambos funcionaram durante muitos séculos, até o momento em que, já no século XX, Bertolt Brecht praticou e sistematizou o chamado Teatro Épico, que na verdade já existia antes dele e se opunha ao sistema teatral proposto por Aristóteles.

Portanto, há - pelo menos - duas grandes teorias teatrais: a de Aristóteles (século IV a.C.) e a de Brecht (século XX). Evidentemente, nesse enorme percurso, muita gente escreveu sobre Teatro e/ou praticou um tipo de espetáculo que não obedecia ao modelo aristotélico, da mesma maneira que muita gente também fez um tipo de teatro que já previa o que Brecht só viria a praticar e teorizar no século XX. A questão não é tão esquemática como está sendo colocada; porém, didaticamente, é preciso lembrar que existiu um grande "pilar" quatro séculos antes de Cristo e que o outro "pilar", diametralmente oposto, só vai aparecer sistematizado em sua totalidade no século XX, no período entre as duas grandes guerras.

Recentemente - e é difícil precisar com exatidão qual é a data em que isso começou a acontecer - apareceu uma nova vertente da prá- tica teatral, que não se baseia nem em Aristóteles, nem em Brecht. Estes propunham um tipo de teatro que partia do texto dramatúrgico; o segundo era tanto escritor quanto encenador. Portanto, o modelo operacional escrever primeiro / dirigir depois, seja com Aristóteles, seja com Brecht, continuou existindo sem objeções de monta, até que, mais recentemente, começou a aparecer com freqüência cada vez maior um tipo de teatro que não nascia da dramaturgia tradicionalmente entendida como tal.

Aristóteles propunha um teatro de empatia, de identificação emocional entre palco e platéia. Brecht propunha o contrário, um teatro em que não houvesse a referida empatia, propiciando, em seu lugar, a reflexão crítica - se lembrarmos que Brecht produziu sua obra no contexto da II Guerra Mundial, no momento em que a Alemanha estava sendo hipnotizada e levada ao delírio por Hitler, fica mais fácil compreender sua aversão à empatia.

O teatro-não dramatúrgico em questão não é voltado à empatia; tenderia, portanto, muito mais para Brecht do que para Aristóteles. Parece querer ter um novo tipo de relação com o público, na qual contaria muito mais aquilo que se vai formando na mente do espectador, do que o enredo e/ou conceito que dramaturgo e encenador tradicionais teriam querido transmitir. Até poderia existir uma proposta na cabeça do Autor do espetáculo (o encenador-dramaturgo); porém, o que parece interessar a ele, enquanto artista, seria o quebra-cabeça formal /conceitual que se forma na mente do espectador, e não a coincidência com a sua intencionalidade.

O modelo proposto por Aristóteles desaguava num teatro que contava um enredo, que tinha uma narrativa embutida nos diálogos; o teatro feito por Brecht também contava um enredo, com certeza de uma maneira diferente e oposta àquela fornecida por Aristóteles, porém sem eliminá-lo. Já o teatro não-dramatúrgico não quer contar história alguma. Ele se instala no palco enquanto um evento cênico, sem intenção narrativa. Sua recusa do enredo resulta em fragmentação, para que não haja nada linear; 
porém, se o espectador assim o quiser, nada impede que ele possa estabelecer elos narrativos em sua cabeça.

O teatro não dramatúrgico não costuma fornecer um enredo organizado, seja em ordem cronológica, seja fora dela; trata-se muito mais de um jogo de armar e, nesse sentido, este é um tipo de teatro absolutamente sintonizado com as propostas da vanguarda que já ecoaram na literatura, como na obra de Julio Cortázar, por exemplo.

O teatro não-dramatúrgico, por não querer ser narrativo, elege um tema (nem sempre fácil de perceber) e faz com que ele volte de forma repetitiva, recorrente; portanto, ao contrário do teatro tradicional, estamos diante de um evento cujo tema é muitas vezes nebuloso e não evolui. É como se fosse um movimento em espiral, em torno de um objeto: volta-se e não se volta sempre ao mesmo lugar. Por paradoxal que possa parecer, é um movimento sempre igual e sempre diferente.

Acabam acontecendo, portanto, reescrituras sucessivas. Tem-se a sensação de que já se viu aquela cena que está voltando; porém, ela volta transformada. Não se sabe o quanto ela volta transformada, se para mais, se para menos. $\mathrm{O}$ importante é estar transformada. Isso acontece muito na música de Philip Glass: fica-se com aquele compasso repetitivo na mente; mas, entre o primeiro compasso e o último, houve modificaçôes. Como estas são mínimas, tem-se a sensação de que se está ouvindo sempre o mesmo compasso (este tipo de música costuma ser muito adequado para teatro, porque no geral uma mesma cena também costuma ter um único 'clima' que não se modifica; portanto, é sempre bom poder dispor de uma música que também não module muito, claro que dependendo, caso a caso, da concepção).

Fala-se muito, atualmente, de desconstrução. Por exemplo, o modelo do teatro com enredo pode ser desconstruido pelo teatro não dramatúrgico, que recusa o enredo. Concordando-se ou não com a proposta de desconstrução em arte, não se pode ignorar que existe um gru- po, seja em música, seja em artes plásticas, seja em teatro, trabalhando claramente com este conceito. Os resultados da desconstrução em arte serão aferidos pela resposta do público, pela crítica e pelo tempo.

Os partidários da desconstrução recusam as estruturas habituais, para trabalhar com novas combinatórias; portanto, é inegável que devem ter algo a dizer, em termos artísticos; por mais desconcertante que seja a arte por eles praticada, vê-se que há, subterraneamente, um projeto. Em sua defesa, pode ser lembrado que só poderia praticar a desconstrução aquele que soubesse recriar a partir do que foi pulverizado. Em síntese, e ainda que de forma simplificada, pode-se pensar em re-combinatórias criativas a partir da desconstrução dos cânones.

No nosso século, alguns nomes influenciaram muito os grupos - brasileiros ou não afinados com a vanguarda internacional: $\mathrm{T}$. Kantor, que vem marcando muito a arte da direção; Pina Bausch, oriunda da área da dança; finalmente, o encenador norte-americano Bob Wilson, que influenciou alguns diretores brasileiros muito atuantes.

Pina Bausch é o nome mais conhecido no Brasil, tendo estado em nosso país por mais de uma vez. Da primeira, houve enorme perplexidade, por não existir um contexto que clareasse o entendimento de suas propostas, o que não aconteceria novamente, uma vez que já é do conhecimento geral a bibliografia existente a seu respeito.

Pina Bausch trabalha nas intersecções entre Teatro e Dança, tendo como resultado uma dança mais teatral e um teatro essencialmente corporal. Enfim, uma arte de fronteira. Porém, deve-se lembrar que Pina Bausch é uma artista alemã com uma história pessoal/nacional específica, marcada pela Guerra. Seus espetáculos são fundamentados sobre uma base niilista, ao contrário dos musicais norte-americanos produzidos pela Disney, fundamentados numa filosofia otimista, que costuma encarar a vida como um mar de rosas possível, um eterno encantamento. 
Pina Bausch, entre outros métodos, trabalha com a colagem, sendo que o resultado final tem um impacto estético muito forte. Alguns de seus admiradores quiseram obter este mesmo impacto; porém, ao invés de absorver seu método de trabalho (usar modelos é um procedimento normal em arte), copiaram seus resultados. O que aconteceu foi um grande equívoco, já que resultados relevantes são, no geral, produto de vivência e criatividade, devendo ser longamente elaborados, em termos de resolução artística, e não meramente copiados.

Grandes invenções viram clichês, que na era do vídeo - vão passando facilmente de país para país. O problema crucial, porém, é entender os métodos alheios, uma vez que resultados artísticos são autorais.

O teatro não-dramatúrgico também trabalha com o conceito de fragmentação, que tem relação com a postura filosófica que compreende o ser humano como uma estrutura fragmentária, e não mais coesa. No teatro, tal postura resultou em personagens fragmentárias. Antes, uma personagem costumava ter coerência, biografia, vida psicológica, objetivos. Estava tudo amarrado, não havia pontas soltas. Atualmente, algumas personagens não só são fragmentárias, como muitos dramaturgos e encenadores sentem-se mais atraídos por personagens deste naipe. Portanto, já se procura a fragmentação, evitando-se personagens, peças, enredos excessivamente coesos, em benefício de fiapos de enredo, de personagens, de temas.

O propósito de fragmentação resulta automaticamente num jogo de armar, em que se destrói o que estava estruturado, transformando-se tudo em módulos, com os quais é possível estabelecer múltiplas re-combinatórias lúdicas.

Uma das grandes contribuições legadas pela ruptura do teatro não-dramatúrgico com os cânones é o que se poderia denominar como descontextualização. Por exemplo, se uma tragédia grega costumava ser encenada num espaço cênico composto de elementos semânticos 'gregos', tal não é mais obrigatório, podendo qual- quer peça acontecer num espaço absolutamente imprevisto, inusitado. Em síntese, não há mais aquela obrigatoriedade rígida de correspondência entre representante e representado, como havia costumeiramente no teatro anterior ao teatro não-dramatúrgico.

$\mathrm{Na}$ descontextualização, tira-se a peça do contexto visual óbvio e opta-se por um outro, no geral simbólico. Ocorre, portanto, uma recontextualização.

Assim, as regras do teatro em geral, sejam elas advindas de Aristóteles ou Brecht, passam a ser desobedecidas voluntariamente. Suspende-se o enredo, a época, a evolução seqüencial. Rompese com tudo aquilo que era considerado usual, para se descobrir como é que as coisas ficam se forem re-combinadas de maneira diferente.

Existe, evidentemente, um grande atrevimento neste tipo de postura; desse atrevimento podem resultar tanto grandes invenções quanto sonoras banalidades. O princípio é perfeitamente operacionalizável; os resultados têm variado muito, em termos de qualidade. $\mathrm{O}$ aspecto excêntrico pode desconcertar crítica e público e dificultar a análise, dando portanto muita margem para o blefe. Como a arte é essencialmente empírica, os artistas devem ter liberdade de criação, cabendo à crítica especializada aprofundar questóes e separar o joio do trigo, identificando as grandes invenções e denunciando o blefe.

Se, durante tantos séculos, a arte sempre contextualizou em termos de correspondência exata, o teatro não-dramatúrgico propôs a discordância, a não correspondência, o descompasso. Este tipo de postura costuma vir acompanhado de um grande desenvolvimento dos aspectos sensoriais (imagem e som), somado à rarefação do referente (o que resulta em conteúdos de difícil acesso). $\mathrm{O}$ original alheio (quando existe) vem sintetizado; no caso de haver o próprio original, ou este é um roteiro sem palavras, ou a palavra não tem mais a mesma função que possuía no teatro tradicional. Em síntese, à predominância da imagem e do som corresponde a diminuição da importância da palavra, que enfraquece ou desaparece; no caso de haver a presença da palavra, 
esta não costuma ter o mesmo valor anterior, vem esvaziada através da verborragia.

Operacionalmente, o sistema poderia ser assim resumido: compactação, procura do conceito, transformação do conceito em imagem, mudança de função da palavra (eliminação pura e simples; esvaziamento através da verborragia; perda da função de portadora de conteúdos e/ ou articuladora do fio narrativo). A palavra, portanto, poderia passar à condição de mais uma peça no jogo de armar.

O teatro tradicional era predominantemente linear, seqüencial, cronológico. Posteriormente, começou-se a trabalhar com a não-linearidade; como exemplo, Vestido de Noiva, de Nelson Rodrigues, é perfeito. Porém, o autor determinou a combinatória desejada por ele, o que determina a seqüência em que o jogo (já) armado deve ser percebido pelo público; ele embaralhou os tempos, mas determinou minuciosamente a seqüência; portanto, não há linearidade, mas há decisão sobre a combinatória desejada, estabelecida como obrigatória, e que resulta na própria "poética" da peça, sem a qual ela não existiria enquanto objeto reconhecível. Aos encenadores sobra, portanto, uma grande margem de criatividade, mas não de alteração da estrutura determinada pelo dramaturgo.

Nesse sentido, qual a contribuição do teatro não-dramatúrgico? Recusa da linearidade e mesmo da não-linearidade, quando estruturada, porque linearidade e estruturação poderiam soar como sinônimos de arte ultrapassada, contrária à vanguarda e à investigação.

A decorrência natural é a problematização da recepção. Se, antigamente, o teatro era um evento compreensível na íntegra, agora ele deixa de sê-lo. Evidentemente, isso se constitui em uma dificuldade para o público, que, perplexo, passa a ter poucas alternativas: abandonar o teatro, porque este ficou incompreensível; optar pelo teatro oposto, comercial, digestivo (o 'besteirol', por exemplo, o que é lamentável); ir ao teatro exatamente porque este ficou mais desafiador. Excentricidade e marketing, neste caso, andariam de mãos dadas.
Este é um caso em que se poderia falar em opacidade. Antes que o público possa compreender o conteúdo, antes de ver o mundo através de uma lente, precisa primeiramente reparar nas características daquela lente. A lente não seria apenas o instrumento que conduz aos conteúdos, mas tem que ser entendida enquanto lente; antes do acesso aos conteúdos, haveria a necessidade de perceber a materialidade do código, que passa a ser problematizante; nesse sentido, a linguagem do espetáculo não estaria lá para facilitar o acesso aos conteúdos, mas sim teria que ser percebida primeiro enquanto realidade própria.

Este universo, ao qual tenho estado a me referir, convive com uma nova postura, que privilegia a arte do incompleto. O público, que estava acostumado com a arte das coisas completas, começou a ter contacto com a arte do incompleto, a arte do inacabado; portanto, "incompleto", "inacabado" e "aleatório" deixaram de soar como sinônimos de "defeito", por serem objetivos procurados de forma voluntária.

$\mathrm{O}$ aleatório remete à incorporação das coincidências involuntárias e dos acasos imprevistos, tratados artisticamente. $\mathrm{O}$ resultado é a convivência (às vezes produtiva, às vezes desconcertante) de unidades díspares entre si e a suspensão do conceito de unidade estilística.

Ao contrário da época do TBC, quando ternos significavam "atualidade" e armaduras significavam "Idade Média”, a pesquisa de época e a unidade de estilo cederam lugar para a convivência de épocas díspares, a multiplicidade de estilos, a incorporação do aleatório e do acaso. A correspondência do cênico com o universo retratado cedeu lugar à intencionalidade significativa.

Um outro elemento notável, dentro deste universo que se está tentando rastrear, é o que poderia ser denominado como cruzamento de variantes: vários "fiapos de enredo" de peças díspares vão sendo entrecruzados, até o momento em que o público já não sabe mais onde está, ou então (e de preferência) tem uma visão mais rica, causada exatamente pelo referido 
entrecuzar de enredos. Em síntese, da peça única e linear, parte-se para as possibilidades combinatórias de várias estruturas, que se entrecruzam sucessivamente, o que é signo evidente da recusa de um determinado tipo de dramaturgia, mais tradicional.

Conseqüentemente, mudam as hierarquias. O dramaturgo cede lugar ao encenador-dramaturgo, capaz de concretizar cenicamente um roteiro próprio ou de transformar em módulos intercambiáveis uma peça escrita por outra pessoa. Nesse caso, a figura do dramaturgo, pelo menos tal como a conhecíamos, tenderia a desaparecer, a ceder lugar para a do encenador-dramaturgo, que passaria a assumir dupla função.

Em síntese, no teatro não dramatúrgico, parte-se de idéias, de roteiros, de desenhos, ou - no máximo - de peças transformadas em módulos. Desaparece aquela estrutura tão conhecida, em que um dramaturgo escreve previamente um texto, para só então um encenador começar a dirigi-lo. A narrativa vai ficando simplificada, vai sendo compactada, até se transformar em conceitos, por sua vez concretizados em imagens poderosas, que se sobrepóem ou mesmo substituem a palavra.

Não sem razão, o século XX é um século muito influenciado pela imagem, é o século do cinema, da televisão, do mesmo modo que o século XIX foi o século da palavra, da literatura. Está-se vivendo agora no teatro a conseqüência dessa mudança. Radicalizando, ou não se tem um texto, ou então o texto passa a ser pretexto para a imagem.

Terminada a fase mais provocativa da instauração do teatro não-dramatúrgico, parece estar surgindo um momento mais sereno, de maturidade, em que os saldos positivos de cada vertente, mesmo que sejam opostas entre si, passam a ficar à disposição, em termos de enriquecimento da linguagem teatral propriamente dita.

$\mathrm{O}$ aparecimento do teatro não-dramatúrgico colocou a classe teatral, os teóricos, os críticos e também o público numa grande encruzilhada, que é a seguinte: postular o imobilismo da arte é obviamente incorreto, porque seus melhores momentos sempre foram aqueles de inconformismo. Mas, ao mesmo tempo, nem todo resultado do inconformismo é de boa qualidade. Então, os produtos artísticos precisam ser identificados e qualificados, na medida do possível. Como fazê-lo, no caso do teatro não-dramatúrgico, diante de sua realidade ainda bastante nebulosa?

Invenção e arte são irmãs gêmeas, são xifópagas, uma vive do corpo da outra, porque não existe arte sem invenção e não existe invenção sem risco. Toda vez que se inventa, está-se correndo riscos. O teatro não-dramatúrgico trouxe investigação, novidade, polêmica, perturbação. Nós, especialistas praticantes da arte do teatro, já podemos nos posicionar e decidir se queremos esse método de trabalho ou não. Público e crítica, em seguida, darão a resposta necessária, com a consciência de cada um funcionando como parâmetro.

Só com o tempo vai-se poder separar as contribuições realmente relevantes das irrelevantes. A excessiva proximidade do objeto em análise ainda não permite uma total visada crítica.

No entanto, é possível especular. Os fatos artísticos sucedem-se por alternância; assim, do mesmo modo que, antes da predominância da imagem, houve o momento em que reinava a palavra politicamente engajada, portadora de conteúdo, articuladora da narrativa e da psicologia da personagem, é muito provável que, numa próxima fase, ocorra um retorno a tudo aquilo que foi anteriormente abandonado. E, principalmente, ao teatro da condição humana, substituído nas últimas décadas pela investigação estética radical (o que não significa que estas duas vertentes não possam - um dia - voltar a caminhar juntas, como já o fizeram nos grandes momentos da história do teatro). 